\title{
Algorithmic bias: should students pay the price?
}

\author{
Helen Smith ${ }^{1}$ (] \\ Received: 15 August 2020 / Accepted: 18 August 2020 / Published online: 12 September 2020 \\ (c) Springer-Verlag London Ltd., part of Springer Nature 2020
}

Thanks to the COVID-19 pandemic, rather than the usual exams, A-Level students in the UK faced the novel process of being awarded grades generated by calculation determined by an algorithm (Coughlan 2020b) as administered by the Office of Qualifications and Examinations Regulation (Ofqual 2020). One need to only explore \#Alevels via Twitter to find cases of students who have been tremendously downgraded by this process; in one incidence from a predicted A grade to a U (@TykeTaffy 2020). The grades awarded understandably generated uproar and resulted in the destabilisation of many members of this year's student cohort who depended on their results to move on with their lives to further education, training, or employment.

The entire fiasco had been due to the application of an algorithm which goes against the United Kingdom's (UK's) Government's very own recently drafted guidelines: The Office for Artificial Intelligence's (2020 p. 36) guidance on the use of $\mathrm{AI}$ in the public sector stipulates that there must be "a process for monitoring unexpected or biased outputs". Ofqual (2020) stated that they "performed an equalities analysis of calculated grades" upon their model which determined this year's grades; they claimed their analysis showed "no evidence that this year's process of awarding grades has introduced bias." However, this was not found to be the case; the distribution of downgrading had been noted to favour students attending private/independent schools (Lee 2020) whilst students from disadvantaged backgrounds had been hit hardest (Adam and McIntyre 2020). Ultimately, the algorithm used to restore grading balance and determine student's final grades was both inconsistent and unfair (Coughlan 2020b).

Public pressure resulted in the first U-turn by the Scottish Government whereby grades would be re-issued and based solely on teacher judgment (Coughlan 2020a). Had it not

Helen Smith

helen.smith@bristol.ac.uk

1 Centre for Ethics in Medicine, University of Bristol, Bristol, UK been for peer pressure applied by the devolved governments to follow suit, the UK Government might not have decided to finally abandon the contested algorithmically issued grades. Without this change of heart, many student's futures would have been sacrificed in the name of maintaining a standard, which had not even been uniformly applied across the UK's four nations, England, Scotland, Wales and Northern Ireland.

Every nation has had their education system impacted by the pandemic, there has been no globally coordinated response for managing exam results to ensure fairness worldwide. Yet, whilst the UK Government concerned itself with devaluation of grades, some other nations simply accepted an overall jump in grades. For example, France utilised results available from exams taken earlier in the student's courses; they enjoyed record pass rates and the subsequent provision of thousands of extra university places (York 2020).

Whilst we all hope that the pandemic's disruption will confine itself to 2020 , challenges may persist without a vaccine widely deployed before the next examination period. If biased algorithms had been deemed acceptable this year, then that precedence risked their continued use in subsequent years; this would have perpetuated a year-on-year growing divide between private/independent schools and those from disadvantaged backgrounds; possibly leaving thousands of young adults behind for no good reason. A bad algorithm applied universally is awful enough, but a bad algorithm applied inconsistently is horrendously unfair to those it affects and sets a poor example to other countries and organisations looking to manage their examination system under similar conditions. The UK Government has only relatively recently begun to truly consider how algorithms are used and the implications of that use; there will be certainly be room for improvement in algorithmic practices for some time to come.

The AI community is well placed to pass comment on the construction and use of algorithms; we have a responsibility to use our experience to predict problems where possible 
and to speak out against negative issues when experienced by affected stakeholders.

Curmudgeon Corner Curmudgeon Corner is a short opinionated column on trends in technology, arts, science and society, commenting on issues of concern to the research community and wider society. Whilst the drive for super-human intelligence promotes potential benefits to wider society, it also raises deep concerns of existential risk, thereby highlighting the need for an ongoing conversation between technology and society. At the core of Curmudgeon concern is the question: What is it to be human in the age of the AI machine? -Editor.

Funding The author received no funding to produce this work.

\section{Compliance with ethical standards}

Conflict of interest The author declares no conflict of interest.

\section{References}

@ TykeTaffy (2020) 13th August 2020. Available at: https://twitt er.com/TykeTaffy/status/1293837655516618752. Accessed 17 Aug 2020

Adams R, McIntyre N (2020) England A-level downgrades hit pupils from disadvantaged areas hardest. The Guardian. https://www. theguardian.com/education/2020/aug/13/england-a-level-downg rades-hit-pupils-from-disadvantaged-areas-hardest\#. Accessed 17 Aug 2020
Coughlan S (2020a) Scottish school pupils have results upgraded. BBC News. https://www.bbc.co.uk/news/amp/uk-scotland-53740588? Accessed 17 Aug 2020

Coughlan S (2020b) Why did the A-level algorithm say no? BBC News. https://www.bbc.co.uk/news/education-53787203. Accessed 17 Aug 2020

Lee G (2020) Did England exam system favour private schools? 4News. https://www.channel4.com/news/factcheck/factcheck-did-engla nd-exam-system-favour-private-schools. Accessed 17 Aug 2020

Office for Artificial Intelligence (2020) A guide to using artificial intelligence in the public sector. https://assets.publishing.servi ce.gov.uk/government/uploads/system/uploads/attachment_data/ file/871177/A_guide_to_using_AI_in_the_public_sector_print _version_.pdf. Accessed 17 Aug 2020

Ofqual (2020) Executive summary: awarding GCSE, AS, A level, advanced extension awards and extended project qualifications in summer 2020: interim report. https://assets.publishing.servi ce.gov.uk/government/uploads/system/uploads/attachment_data/ file/909035/6656-2_-_Executive_summary.pdf. Accessed 17 Aug 2020

York J (2020) Record number of French students pass final exams. The Connexion. https://www.connexionfrance.com/index.php/Frenc h-news/Record-number-of-French-students-pass-final-exams. Accessed 17 Aug 2020

Publisher's Note Springer Nature remains neutral with regard to jurisdictional claims in published maps and institutional affiliations. 